\title{
EFFECTS OF GALLIC ACID ON EXPLORATORY BEHAVIOR AND LOCOMOTOR ACTIVITY IN RATS
}

\author{
A. Georgieva ${ }^{1}$, S. Belcheva ${ }^{2,3}$, R. Tashev ${ }^{2,4}$, S. Valcheva-Kuzmanova ${ }^{1}$ \\ ${ }^{1}$ Department of Preclinical and Clinical Pharmacology, Medical University Prof. Dr. Paraskev \\ Stoyanov, Varna, Bulgaria \\ ${ }^{2}$ Department of Behavior Neurobiology, Institute of Neurobiology, Bulgarian Academy of Sciences, \\ Sofia, Bulgaria \\ ${ }^{3}$ Faculty of Pre-School and Primary School Education, SU "Sv. Kl. Ohridsky", Sofia, Bulgaria \\ ${ }^{4}$ Department of Pathophysiology, Medical University of Sofia, Sofia, Bulgaria
}

\begin{abstract}
PURPOSE: The present study investigated the effects of GA on exploratory behavior and locomotor activity in male Wistar rats. METHODS: GA $(20 \mathrm{mg} / \mathrm{kg})$ or saline were administrated orally to different groups of rats for 7, 14, 21 and 30 days. At the end of each experimental period, the changes in rat behavior were recorded in an Opto Varimex apparatus. The number of horizontal and vertical movements recorded every minute served as a measure of exploratory activity and habituation. The total number of movements was used as a measure of locomotor activity. RESULTS: It was found that after 7 days of treatment, GA did not significantly affect exploratory behavior and locomotor activity of rats compared to the saline-treated controls. After the 14 day treatment period, GA did not significantly affect horizontal activity but reduced the number of vertical movements. After 21 and 30 days, GA significantly reduced both horizontal and vertical movements of rats compared to the controls. At all testing periods, GA did not disturb habituation which is considered as an elementary form of learning. CONCLUSION: The present study suggested that GA applied subchronically to rats has a sedative effect and does not disturb the memory and learning processes.
\end{abstract}

Key words: Wistar rats, Opto Varimex apparatus, movements, habituation, sedative effect, learning, memory

\section{INTRODUCTION}

Gallic acid (GA) also known as hydroxybenzoic acid is a phenolic acid, a polyphenol compound. The dietary sources are olives (1), berries, mango, plums, grapes, nuts, wine $(2,3)$. Many types of tea (black, green, white) are also an important source of GA $(2,3)$. Polyphenols are represented by four main classes of substances - flavonoids, phenolic acids, stilbens and lignans. Plant polyphenols are able to access the brain via the blood brain barrier and represent novel therapeutic agents in central nervous system diseases (4). The ability of polyphenols and their metabolites to cross the blood brain barrier was demonstrated in 2010 by Janle et al. (5) as they found 14C-labeled plant

\footnotetext{
* Correspondence to: assist. prof. Antoaneta Georgieva, Department of Preclinical and Clinical Pharmacology, Medical University Prof. Dr.

Paraskev Stoyanov, 9002 Varna, 55 M. Drinov Str., Bulgaria; Tel. 0899818886; E-mail:

dr_a_georgieva@abv.bg
}

polyphenols in the brain tissue and brain microdialysate. There are findings that grape seed polyphenols, namely GA, catechin and epicatechin, do accumulate in the brain following long-term consumption (6).

The aim of the present study was to investigate the effects of the subchronic administration of GA on exploratory behavior and locomotor activity in male Wistar rats.

\section{MATERIALS AND METHODS Gallic acid}

Gallic acid from the laboratories of Sigma Aldrich was used in the experiment.

\section{Animals and treatment}

Male Wistar rats (180-220 g at the beginning of experiments) were housed in polypropylene boxes with free access to food and drinking water. The experiments were carried out according to the rules of the Ethics Committee of the Institute of Neurobiology, Bulgarian Academy of Sciences, in compliance with the 
national policies and the EEC Directive of 1986 (86/609/EEC).

80 rats divided into 8 groups of 10 animals each were used for the experiments. The rats were treated orally through an orogastric cannula in the course of 7 days (one week), 14 days (2 weeks), 21 days (three weeks) or 30 days (one month). There were two groups of rats for each treatment period: Control and GA. The control groups were treated with saline 10 $\mathrm{ml} / \mathrm{kg}$. Rats from GA groups were treated with GA at a dose of $20 \mathrm{mg} / \mathrm{kg}$ as a $10 \mathrm{ml} / \mathrm{kg}$ solution.

\section{Testing of exploratory behavior and locomotor activity}

Exploratory behavior and locomotor activity were recorded in an Opto Varimex apparatus (Columbus Instruments, USA), according to the method of Köhler \& Lorens (7). The experimental chamber was $50 \mathrm{~cm} \times 50 \mathrm{~cm} \times$ $25 \mathrm{~cm}$. This apparatus records the number of photobeam interruptions while the animal moves. It provides selective counting of the number of horizontal movements (ambulation) and vertical movements (rearings) in arbitrary units (AU). The information obtained was automatically recorded every minute for the first $5 \mathrm{~min}$ of the test and for the next $5 \mathrm{~min}$ thereafter. The number of horizontal and vertical movements recorded every minute for the first $5 \mathrm{~min}$ served as a measure of exploratory activity and habituation to the new environment. The total number of movements during the first $5 \mathrm{~min}$ and during the whole 10-
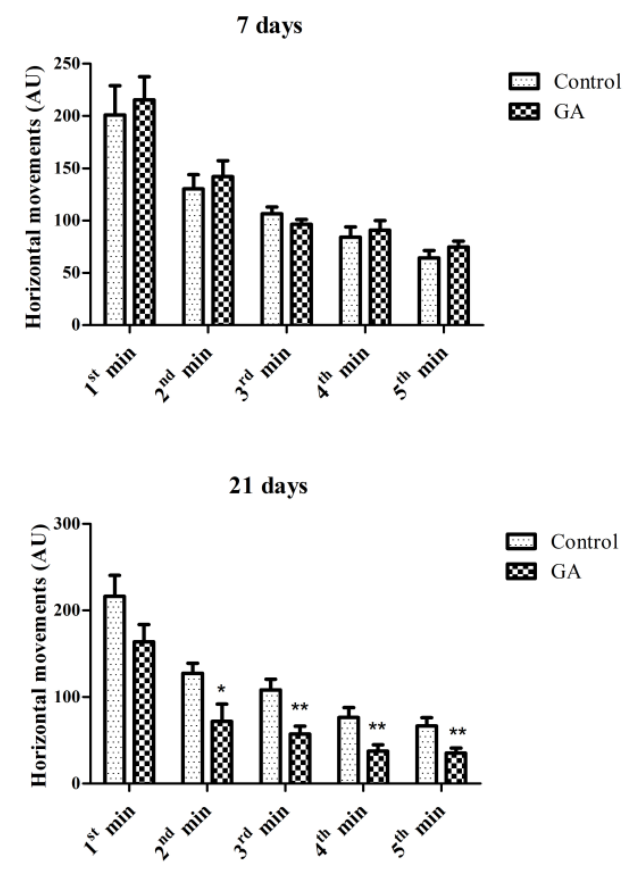

min period of observation was used as a measure of locomotor activity. The experiments were carried out at the same time (between 9:00 a.m. and 1:00 p.m.). The rats were placed in the central quadrant of the activity monitor. The different groups were tested on the $7^{\text {th }}, 14^{\text {th }}, 21^{\text {st }}$ and $30^{\text {th }}$ day $60 \mathrm{~min}$ after the last treatment. Before each test, the apparatus was wiped clean and dried.

\section{Statistical analysis}

Separate t-tests were used to process the data obtained for horizontal and for vertical movements for the $1^{\text {st }}, 2^{\text {nd }}, 3^{\text {rd }}, 4^{\text {th }}$ and $5^{\text {th }} \min$ and for the whole 5-min and 10-min periods of observation. A level of $\mathrm{p}<0.05$ was considered significant. GraphPad Prism statistical software was used.

\section{RESULTS}

\section{Effect of GA on exploratory behavior}

Effect of GA on the horizontal movements for every minute during the first $5 \mathrm{~min}$

After 7 and 14 days of treatment GA at a dose of $20 \mathrm{mg} / \mathrm{kg}$ had no significant effect on the number of horizontal movements for the $1^{\text {st }}$, $2^{\text {nd }}, 3^{\text {rd }}, 4^{\text {th }}$ and $5^{\text {th }}$ min as compared with the respective saline-treated controls. After the 21days treatment period GA significantly reduced the number of horizontal movements for the $2^{\text {nd }}(\mathrm{p}<0.05), 3^{\text {rd }}, 4^{\text {th }}$ and $5^{\text {th }} \min (\mathrm{p}<$ 0.01 ). After the 30-days treatment period GA significantly reduced the number of horizontal movements for the $1^{\text {st }}, 2^{\text {nd }}$ and $3^{\text {rd }} \min (\mathrm{p}<$ 0.05) (Figure 1).
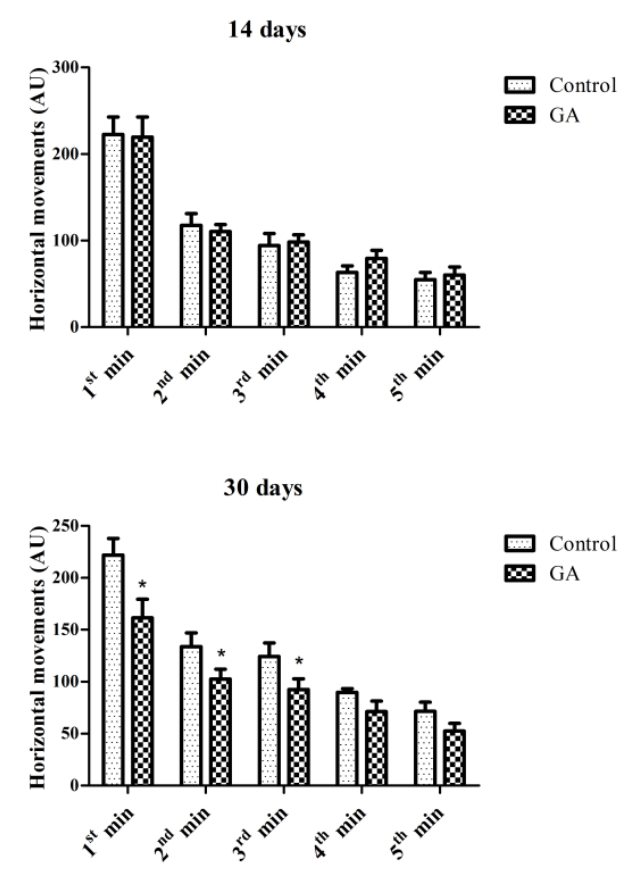

Figure1. Effect of gallic acid (GA) at a dose of $20 \mathrm{mg} / \mathrm{kg}$ applied orally to rats for 7, 14, 21 and 30 days on the number of horizontal movements recorded every minute for a 5 -min observation period; $\mathrm{AU}$ - arbitrary units; $\mathrm{n}$ $=10 ; * \mathrm{p}<0.05$ vs control; $* * \mathrm{p}<0.01$ vs control. 
The number of horizontal movements is gradually reduced with time in every group independent of the kind and duration of treatment which shows that the habituation to the new environment is not disturbed (Figure 1).

Effect of GA on the vertical movements for every minute during the first $5 \mathrm{~min}$

GA at a dose of $20 \mathrm{mg} / \mathrm{kg}$ had no significant effect on the number of vertical movements for the $1^{\text {st }}, 2^{\text {nd }}, 3^{\text {rd }}, 4^{\text {th }}$ and $5^{\text {th }}$ min after 7 days of treatment as compared with the respective saline-treated controls. After the 14-days
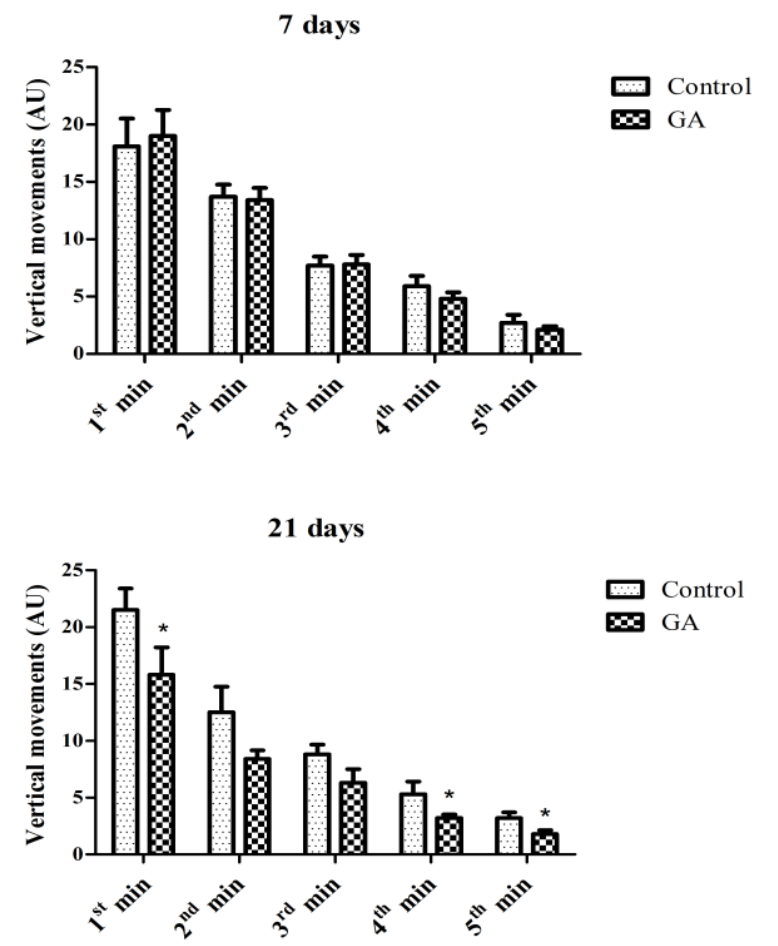

GEORGIEVA A.

treatment period GA significantly reduced the number of vertical movements for the $1^{\text {st }}, 3^{\text {rd }}$ and $5^{\text {th }}$ min $(\mathrm{p}<0.05)$. After 21 days of treatment GA significantly reduced the number of vertical movements for the $1^{\text {st }}, 4^{\text {th }}$ and $5^{\text {th }}$ min $(\mathrm{p}<0.05)$. After the 30-days treatment period GA significantly reduced the number of vertical movements for the $1^{\text {st }}, 2^{\text {nd }}, 3^{\text {rd }}, 4^{\text {th }}$ and $5^{\text {th }} \min (\mathrm{p}<0.05)$ (Figure 2).

The number of vertical movements gradually reduced with time for every group and every period of treatment which is a marker for habituation to the new environment (Figure 2).

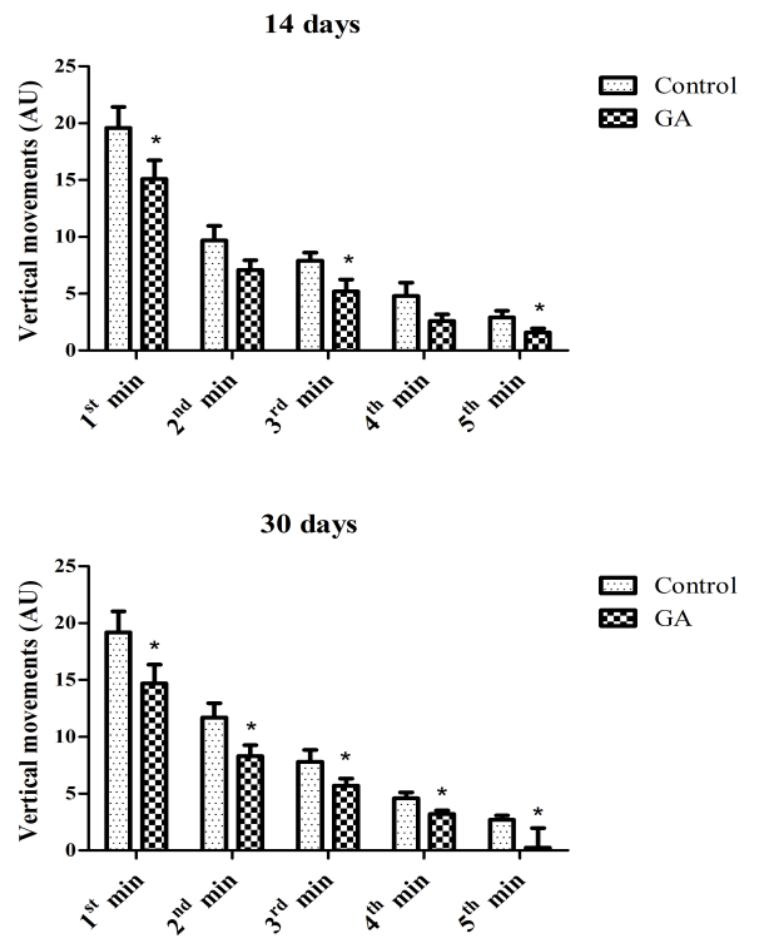

Figure 2. Effect of gallic acid (GA) at a dose of $20 \mathrm{mg} / \mathrm{kg}$ applied orally to rats for 7, 14, 21 and 30 days on the number of vertical movements recorded every minute for a 5-min observation period; $\mathrm{AU}-$ arbitrary units; $\mathrm{n}=$ $10 ; * \mathrm{p}<0.05$ vs control.

\section{Effect of GA on locomotor activity}

Effect of GA on the number of horizontal movements for the periods of $5 \mathrm{~min}$ and $10 \mathrm{~min}$ The post-hoc t-test revealed that GA administered to rats at a dose of $20 \mathrm{mg} / \mathrm{kg}$ for 7 and 14 days had no significant effect on the horizontal locomotor activity recorded during the first $5 \mathrm{~min}$ and during the whole 10-min observation period. It significantly reduced the number of horizontal movements for the 5-min period $(\mathrm{p}<0.001)$ and for the whole 10-min period $(\mathrm{p}<0.01)$ after 21 -day treatment. After 30 days of treatment GA also significantly reduced the number of horizontal movements for the 5-min period and for the whole 10-min period of observation $(p<0.01)$ (Figure 3).

\section{Effect of $G A$ on the number of vertical movements for the periods of $5 \mathrm{~min}$ and 10 $\min$}

The post-hoc t-test revealed that GA administered to rats for 7 days had no significant effect on the vertical activity recorded during the first $5 \mathrm{~min}$ and during the whole10-min observation period. It significantly reduced the number of vertical movements for the 5-min period and for the whole 10 -min period $(p<0.001)$ when applied to rats for 14 days. GA also significantly reduced the number of vertical movements for the 5-min period and for the whole 10-min period $(\mathrm{p}<0.001)$ after 21-day treatment period and significantly reduced the number of vertical movements for the 5-min period ( $\mathrm{p}<$ 0.01 ) and for the whole 10-min period of observation $(\mathrm{p}<0.001)$ after 30 days of treatment (Figure 3). 

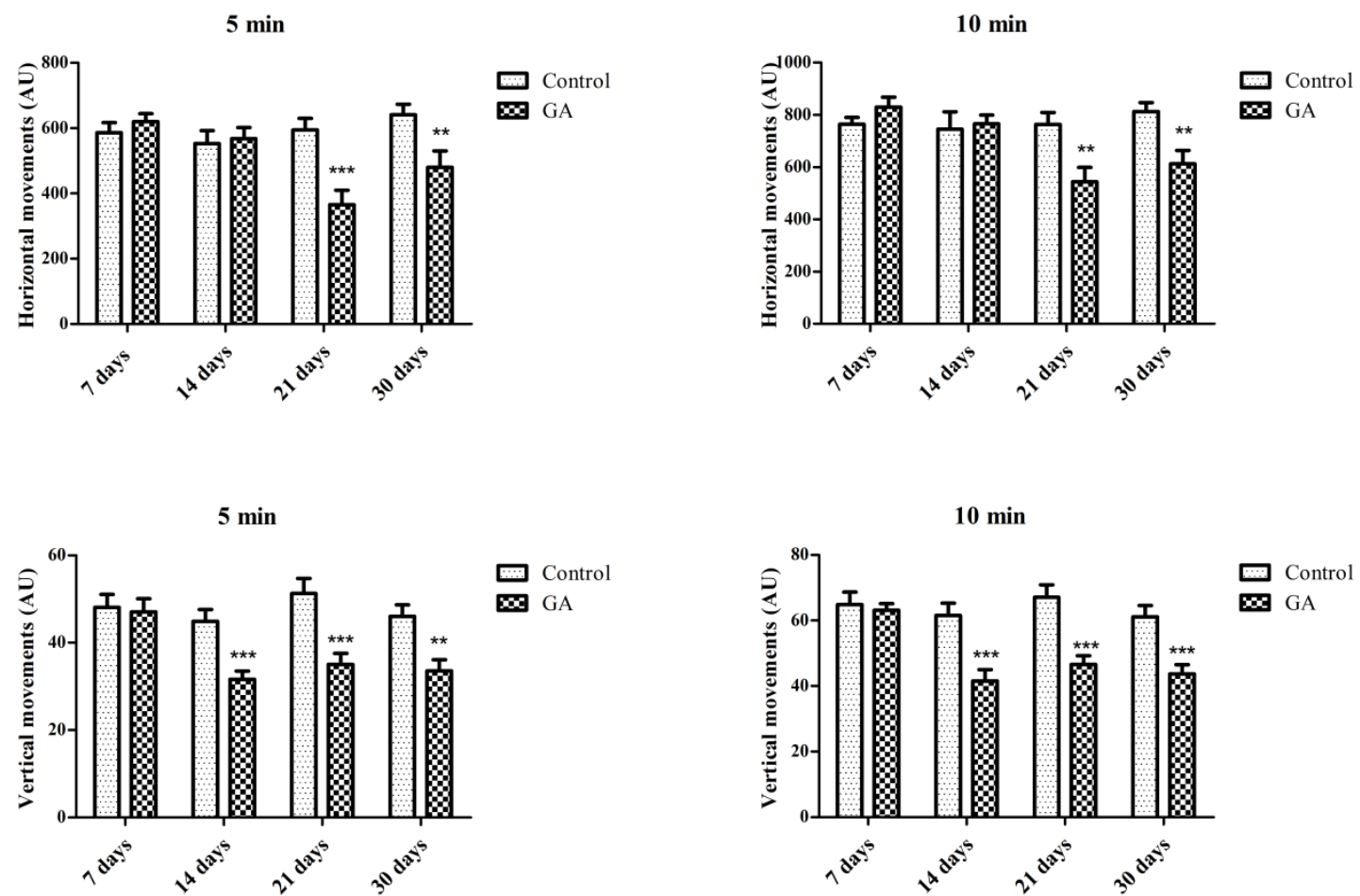

Figure 3. Effect of gallic acid (GA) at a dose of $20 \mathrm{mg} / \mathrm{kg}$ applied orally to rats for 7, 14, 21 and 30 days on the total number of horizontal and vertical movements recorded for the first 5-min period and for the whole 10-min period of observation; AU - arbitrary units; $\mathrm{n}=10$; **p $<0.01$ vs control; ***p $<0.001$ vs control.

\section{DISCUSSION}

In the present study, exploratory behavior and locomotor activity of rats were tested using an Opto Varimex apparatus. This test is a common measure of exploratory behavior and general activity in rodents (8). Its concept lies in the natural pattern of behavior of animals to highly explore an unfamiliar environment (the chamber of the apparatus) initially, and eventually habituate to it $(9,10)$. Exploration has been defined as active investigation (e.g., locomotion) that might lead to an animal gaining information about its environment (11). The short length of time emphasizes exploratory behavior (8).

The results from the present study showed that GA applied at a dose of $20 \mathrm{mg} / \mathrm{kg}$ for 14,21 and 30 days reduced the locomotor activity of rats compared with the respective salinetreated controls. These changes in locomotor activity may be due to a sedative effect of GA. This is in some contradiction with the results of Mansouri et al. (2014) who found that GA in doses $30-300 \mathrm{mg} / \mathrm{kg}$ had an anxiolytic-like but not sedative effect (12). In the same study GA caused sedation in a dose of $500 \mathrm{mg} / \mathrm{kg}$. The anxiolytic-like effect was comparable to that of benzodiazepine (BDZ) drug diazepam and $5-\mathrm{HT}_{1 \mathrm{~A}}$ agonist buspirone. These findings suggest that the sedative effect of GA might be due to activation of $\mathrm{BDZ}$ receptors.

Habituation to a novel environment is considered an elementary form of learning, therefore the decreased exploration is taken as an index of memory $(13,14)$. The present study showed that GA for the four treatment periods did not compromise the habituation of rats to the new environment of the Opto Varimex apparatus. These results suggested that GA did not disturb memory. This is in coincidence with the data of Korani et al. (2014) who found that GA ameliorated the spatial memory deficit in a model of vascular dementia (15). Mansouri et al. (2013) found that GA prevented the cognitive deficit in a model of Alzheimer's disease (16). This beneficial effect on memory could be related to the antioxidant activity of GA and a possible neuroprotective effect $(17,18)$.

The accumulation of polyphenolic substances in the brain following long-term consumption could explain the absence of effect in the animals treated for 7 days and its onset after 14-day treatment with GA (19). 


\section{CONCLUSION}

The results from the present study show that after subchronic administration GA reduced the locomotor activity and exploratory behavior of rats which might be due to a sedative effect. GA did not disturb the habituation of the animals to the new environment and thus did not adversely affect this elementary form of learning in young/healthy rats.

\section{ACKNOWLEDGMENTS}

This study was supported by Grant MU-Varna 2012/2014.

\section{REFERENCES}

1. Wang, X., Wang, J. and Yang N., Flow injection chemiluminescent detection of gallic acid in olive fruits. Food Chem, 105(1):340345, 2007.

2. Manach, C., Scalbert, A., Morand, C., Rémésy, C. and Jiménez, L., Polyphenols: food sources and bioavailability. Am J Clin Nutr, 79:727-747, 2004.

3. Daglia, M., di Lorenzo, A., Nabavi, S.F., Talas, Z.S. and Nabavi, S.M., Polyphenols: Well beyond the antioxidant capacity: Gallic acid and related compounds as neuroprotective agents: You are what you eat! (Review). Curr Pharm Biotechnol, 15(4):362372, 2014.

4. Vafeiadou, K, Vauzour, D. and Spencer, J.P.E., Neuroinflammation and its modulation by flavonoids. Endocr Metab Immune Disord Drug Targets, 7(3):211-224, 2007.

5. Janle, E.M., Lila, M.A., Grannan, M., Wood, L., Higgins, A., Yousef, G.G., Rogers, R.B., Kim, H., Jackson, G.S., Ho, L. and Weaver, C.M., Pharmacokinetics and tissue distribution of 14C-Labeled grape polyphenols in the periphery and the central nervous system following oral administration. J Med Food, 13(4):926-933, 2010.

6. Ferruzzi, M.G., Lobo, J.K., Janle, E.M., Cooper, B., Simon, J.E., Wu, Q.-L., Welch, C., Ho, L., Weaver, C. and Pasinetti, G.M., Bioavailability of gallic acid and catechins from grape seed polyphenol extract is improved by repeated dosing in rats: Implications for treatment in Alzheimer's disease. J Alzheimers Dis, 18(1):113-124, 2009.

7. Kohler, C. and Lorens, S.A., Open field activity and avoidance behavior following serotonin depletion: A comparison of the effects of parachlorpheylalanin and electrolitic midbrain raphe lesions. Pharmacol Biochem Behav, 8:223-233, 1978.

8. Gould, T.D., Dao, T.D. and Kavacsics, C.E., Mood and anxiety related phenotypes in mice. Humana Press LLC:1-2, 2009.
9. Bolivar, V.J., Caldarone, B.J., Reilly, A.A. and Flaherty, L., Habituation of activity in an open field: A survey of inbred strains and F1 hybrids. Behav Genet, 30(4):285-293, 2000.

10. Daenen, E.W.P.M., Van der Heyden, J.A., Kruse, C.G., Wolterink, G. and Van Ree, J.M., Adaptation and habituation to an open field and responses to various stressful events in animals with neonatal lesions in the amygdala or ventral hippocampus. Brain Res, 918:153-165, 2001.

11.Lynn, D.A. and Brown, G.R., The ontogeny of exploratory behavior in male and female adolescent rats (Rattus norvegicus). Dev Psychobiol, 51(6):513-520, 2009.

12. Mansouri, M.T., Soltani, M., Naghizadeh, B., Farbood, Y., Mashak, A. and Sarkak,i A., A possible mechanism for the anxiolytic-like effect of gallic acid in the rat elevated plus maze. Pharmacol Biochem Behav, 117:4046, 2014.

13. Thiel, C.M., Huston, J.P. and Schwarting, R.J.K., Hippocampal acetylcholine and habituation learning. Neuroscience 85:12531262, 1998.

14. Thiel, C.M., Müller, C.P., Huston, J.P. and Schwarting, R.J.K., High versus low reactivity to a novel environment: behavioural pharmacology and neurochemical assessments. Neuroscience 93:243-251, 1999.

15. Korani, M.S., Farbood, Y., Sarkaki, A., Moghaddam, H.F. and Mansouri M.T., Protective effects of gallic acid against chronic cerebral hypoperfusion-induced cognitive deficit and brain oxidative damage in rats. Eur J Pharmacol 733:62-67, 2014.

16. Mansouri, M.T., Naghizadeh, B., Ghorbanzadeh, B., Farbood, Y., Sarkaki, A. and Bavarsad, K., Gallic acid prevents memory deficits and oxidative stress induced by intracerebroventricular injection of streptozotocin in rats. Pharmacol Biochem Behav, 111:90-96, 2013.

17. Kumagai, J., Kawaura, T., Miyazaki, T., Prost, M., Prost, E., Watanabe M. and Quetin-Leclercq, J., Test for antioxidant ability by scavenging long-lived mutagenic radicals in mammalian cells and by blood test with intentional radicals: an application of gallic acid. Radiat Phys Chem 66(1):17-25, 2003.

18. Mansouri, M.T., Farbood, Y., Sameri, M.J., Sarkaki, A., Naghizadeh, B. and Rafeirad, M., Neuroprotective effects of oral gallic acid against oxidative stress induced by 6hydroxydopamine in rats. Food Chem 138(23):1028-1033, 2013.

19. Willis, L.M., Shukitt-Hale, B. and Joseph, J.A., Recent advances in berry supplementation and age-related cognitive decline (Note). Curr Opin Clin Nutr Metab Care, 12: 91-94, 2009. 